\title{
Pneumonia Due To Stenotrophomonas maltophila in the Immunocompetent Patient: A Case of Environmental Exposure \\ Ana Cardoso ${ }^{1}$, João Victor Freitas ${ }^{1}$, Raquel Soares ${ }^{1}$, Tiago Branco ${ }^{1}$, Francisco Cunha ${ }^{1}$, Liliana R Santos ${ }^{1}$ and António Pais de Lacerda ${ }^{1,2}$
}

${ }^{1}$ Division of Internal Medicine II, Department of Medicine, Centro Hospitalar Universitário Lisboa Norte, EPE, Portugal

${ }^{2}$ Faculty of Medicine of the University of Lisbon, Portugal

*Corresponding author: Ana Cardoso, Division of Internal Medicine II, Department of Medicine, Centro Hospitalar Universitário Lisboa Norte, EPE, Portugal

Stenotrophomonas maltophilia is a multi-resistant gram-negative bacterium, an opportunistic agent generally associated with nosocomial infections, particularly in immunocompromised patients, being usually found in the intensive care setting. However, its prevalence in patients without predisposing risk factors is very rare. We have identified and successfully treated a healthy, immunocompetent patient who developed a community acquired severe $S$. maltophilia pneumonia $[1,2]$.

We report the case of a 24-year-old man who presented to our department with a 7 day history of fever, headache, chest pain and non-productive cough. There was no relevant clinical history or medication. On physical exam he had tachypnoea, inspiratory crackles in the left lung base and a peripheral oxygen saturation $\left(\mathrm{SpO}_{2}\right)$ of $89 \%$. Laboratory findings revealed normal white blood cell count, an increased high-sensitivity C-reactive protein $(27.9 \mathrm{mg} / \mathrm{dL}$ N.R. $<0.5 \mathrm{mg} / \mathrm{dL})$, lactate dehydrogenase $(296 \mathrm{U} / \mathrm{L}>250 \mathrm{U} / \mathrm{L})$ and erythrocyte sedimentation rate $(120 \mathrm{~mm} / \mathrm{h}<20 \mathrm{~mm} / \mathrm{h})$ with procalcitonin value within the reference range $(0.09$ $\mathrm{ng} / \mathrm{mL}<0.5 \mathrm{ng} / \mathrm{mL}$ ). Chest radiography showed diffuse opacity of the lower third of the left lung. Chest CT displayed diffuse bilateral ground-glass opacities with baseline bilateral rounded consolidations (Figure 1).

The patient was admitted with the presumptive diagnosis of community-acquired pneumonia and started empirical antibiotic regimen with amoxicillin clavulanate and azithromycin, with no clinical or laboratory improvement. Later microbiological studies revealed bacteremia due to Stenotrophomonas maltophila.

On a more detailed clinical history, the patient acknowledged to work in a poultry factory. This isolate was considered in a probable context of laboratory exposure. However, it was decided to extend the etiological study, excluding other causes, namely immunosuppression, autoimmune and cystic fibrosis. The patient initiated targeted antibiotic therapy with sulfamethoxazole and trimethoprim, with suspension of the previous antibiotics, with rapid symptomatic improvement and was discharged home with rest $\mathrm{SpO}_{2}$ of $98 \%$.

Stenotrophomonas maltophilia is an environmental microorganism found in watery habitats, including rhizosphere of plants, animals, food and water sources. Reported cases of community-acquired $S$. maltophilia involved patients with comorbidities that conferred some degree of immunosuppression $[1,3]$. However, our patient did not have any of these predisposing risk factors and investigations for a state of immunocompromise were negative. We admit that this infection may be due to the environmental exposure to which the patient was subject in his workplace, a poultry factory. This case suggests that infection by this

Citation: Cardoso A, Freitas JV, Soares R, Branco T, Cunha F, et al. (2021) Pneumonia Due To Stenotrophomonas maltophila in the Immunocompetent Patient: A Case of Environmental Exposure. Int J Respir Pulm Med 8:164. doi.org/10.23937/2378-3516/1410164

Accepted: December 08, 2021; Published: December 10, 2021

Copyright: (C) 2021 Cardoso A. This is an open-access article distributed under the terms of the Creative Commons Attribution License, which permits unrestricted use, distribution, and reproduction in any medium, provided the original author and source are credited 

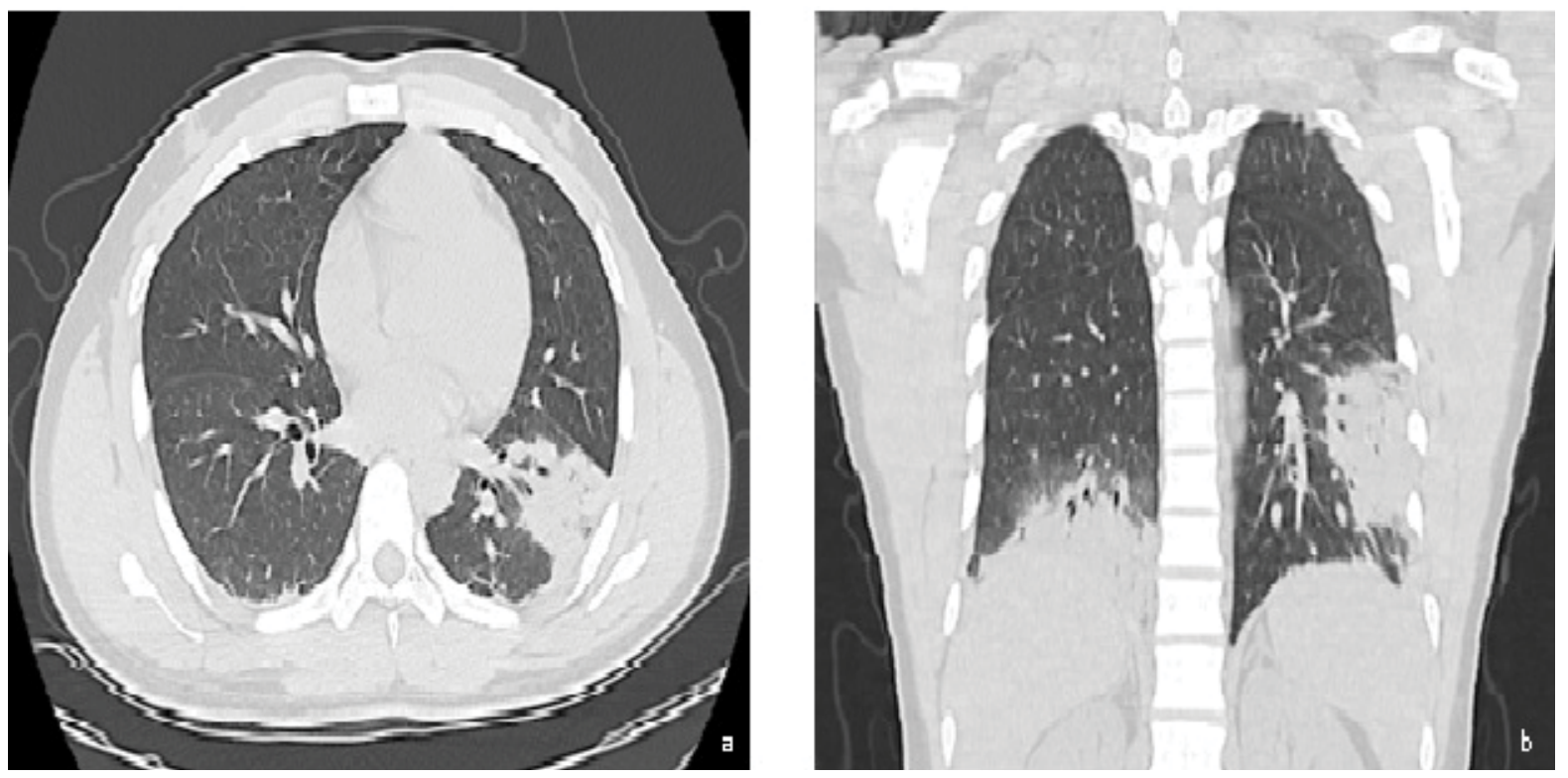

Figure 1: Chest CT: a) Axial and b) Coronal; images demonstrating diffuse bilateral ground-glass opacities with baseline bilateral rounded consolidations.

agent can occur in an immunocompetent patient and therefore it is important for clinicians to be aware of this possibility, as it should be considered in patients diagnosed with pneumonia, without response to firstline antibiotic therapy.

\section{References}

1. Mishra M (2018) Stenotrophomonas pneumonia in an immunocompetent individual. Chest Infections 154.

2. Adegoke A, Stenstrom T, Okoh A (2017) Stenotrophomonas maltophilia as an emerging ubiquitous pathogen: Looking beyond contemporary antibiotic therapy. Front Microbiol 8: 2276.

3. Kang YR, Cha YK, Kim JS, Lee EK, Oh JY, et al. (2020) Imaging findings of stenotrophomonas maltophilia pneumonia: Emphasis on CT findings between immunocompromised and immunocompetent patients. Acta Radiol 61: 903-909. 